\title{
Comparison of social inequality in HPV vaccination among teenagers with parental reports and healthcare providers' records in the 2019 National Immunization Survey-Teen.
}

\author{
Sol Choi ${ }^{1}$, BongKyoo Choi $^{2,3}$
}

1. University High School, Irvine, CA, USA

2. Center for Work and Health Research, Irvine, CA, USA

3. Department of Medicine, University of California, Irvine, CA, USA

*Correspondence: BongKyoo Choi, ScD MPH RPh. Center for Work and Health Research. 35 Schubert Court, Irvine, CA, 92617. E-mail: b.choi@ uci.edu.

\begin{abstract}
Background: Relatively little is known and inconclusive about social inequality in human papillomavirus (HPV) vaccination among teenagers in the United States. This study aims to investigate whether there is a social disparity in HPV vaccination among teenagers and if so, whether it can differ by the source of teen vaccination information (parental reports and provider records).

Methods: We used the data from the 2019 National Immunization Survey-Teen (NIS-Teen; 42,668 teenagers, aged 13-17) including parental reported vaccination status. Among them, 18,877 teenagers had adequate provider reported vaccination records. Two socioeconomic status (SES) measures were used: mother's education and annual family income. Multivariate logistic analyses were conducted.

Results: False negatives of parental reports against provider records were more than two times higher $(p<0.001)$ in low SES teens than in high SES teens. In both SES measures, the proportion of HPV unvaccinated teenagers were lowest in the highest SES level in analyses with parental reports. However, it was the opposite in analyses with provider records. Interestingly, regardless of vaccination information source, the HPV unvaccinated rate was highest in the middle SES teens ( $>12$ years, non-college graduates; and above poverty level, but not $>\$ 75 \mathrm{~K}$ ). Conclusion: A significant social inequality in HPV vaccination among teenagers exists in the United States. The pattern of social inequality in HPV vaccination can be distorted when only parent reported vaccination information is used.
\end{abstract}

Keywords: Human Papillomavirus, vaccine, social inequality, NIS-Teen, false negative, SES.

\section{Introduction}


Human papillomavirus (HPV) infection, resulting in cervical and other cancers, is the most common sexually transmitted disease (STD) [1]. While most HPV cases results in genital warts that may go away in time, persistent HPV infections have been the leading cause of " $90.6 \%$ of cervical, $91.1 \%$ of anal, $75.0 \%$ of vaginal, $70.1 \%$ of oropharyngeal, $68.8 \%$ of vulvar, $63.3 \%$ of penile, $32.0 \%$ of oral cavity, and $20.9 \%$ of laryngeal cancers." [2] (p.1). HPV infections have caused nearly 46,143 cancers each year from 2014-2018, affecting nearly 25,719 women and 20,424 men per year [3].

In the United States, HPV inactivated vaccines such as Gardasil (four-valent), Cervarix (bivalent), and Gardasil 9 (nine-valent) have been developed for prevention of HPV-associated cervical and other cancers, but since 2016, only Gardasil 9 has been distributed, targeting nine high-risk HPV types [4]. From ages 9 through 15, HPV vaccines are administered in a two-dose series while from ages 15 to 45 years old, a three-dose series is recommended. As a result, a recent study reported that "...From the prevaccine era to 2015-2018, significant decreases in 4vHPV-type prevalence occurred among females aged 14-19 years (88\%) and 20-24 years $(81 \%) "[5]$.

But the HPV vaccination of teenagers and its promising future benefits may significantly differ between SES strata. Monitoring social inequality in HPV vaccination among teenagers while working towards health equity of HPV vaccination is a primary national task for public health in the United States [6].

Several investigators [7-9] have examined social inequality in HPV vaccination among teens, particularly using the National Immunization Survey (NIS) Teen, designed to generate accurate, nationally-representative information on vaccination coverage (including HPV vaccine) of teens in the US. However, the results of the previous studies have been inconclusive. For example, in the two studies [7-8] using the parental reported vaccination status, the HPV vaccination rate was greater in high socioeconomic status (SES) teens than in low SES teens. By contrast, in one study [9] using the provider reported vaccination status, the HPV vaccination rate was greater in low SES teens than in high SES. It is not clear yet why they came to different conclusions about social inequality in HPV vaccination among teens, although both studies were based on the same data source of the NIS-Teen.

However, several studies [10-11] have analyzed discrepancies between parental reported vaccination status and provider reported vaccination records, which may bias towards either severe overestimation or underestimation based on the type of disease-preventing vaccine. Dorell et al [10] reported that more than $20 \%$ of parental reported HPV vaccination status of teens in the 2008 NIS-Teen data were false-negative against provider reported vaccination records. Ojha et al [11] further demonstrated that the false-negative propensity of parental reported vaccination status was greater in low SES teens than in high SES teens. All of these implies that social 
inequality in HPV vaccination among teens may significantly differ by which source of vaccination information in the NIS-Teen is used. However, no studies have examined and compared social inequality in HPV vaccination by using both the parental and the provider reported vaccination information of the NIS-Teen.

This study aims to investigate 1) whether there is a significant difference in HPV vaccination by SES among teens and if so, 2) whether it differs by the source of teen vaccination information (parental report, vaccination provider report) in the recent 2019 NIS-Teen data of the United States.

\section{Materials and Methods}

The National Immunization Survey-Teen (NIS-Teen) data.

The NIS-Teen was launched in 2006 and has been sponsored by the National Center for Immunization and Respiratory Diseases of the Centers for Disease Control and Prevention (CDC). It has been used to monitor vaccination coverage among teens 13-17 years living in the United States [12]. The NIS-Teen, an annual nationwide survey, uses two phases of data collection to obtain vaccination information for a large nationally representative sample of teens 13-17 years: (1) a random digit dialing (RDD) telephone survey of households with teens 13-17 years ("parental reported vaccination information of teens"), followed by (2) a mailed immunization history survey to teens' vaccination providers ("provider reported vaccination information of teens"). The RDD survey was designed to identify households with 13-17 yearold teens. Once the households were identified, one parental (parent or guardian) per household who was most knowledgeable about the vaccination history of his/her eligible teen was phoneinterviewed. At the end of the interview, the parental was asked to provide oral consent for contacting his/her eligible teen's vaccination providers. With parental oral consent, a questionnaire was mailed to each vaccination provider to collect the information on the types of vaccinations, number of doses, dates of administration, and other administrative data about the health care facility [12].

\section{The 2019 NIS-Teen data $(N=42,668)$}

For the current study, we used the public-use data file from the 2019 NIS-Teen since it is the latest one available to the public for research prior to the full-scale coronavirus disease 2019 pandemic. For the 2019 NIS-Teen, the RDD household phone interview was conducted from January 3, 2019 to February 6, 2020, while data from teens' vaccination providers were collected from January 2019 to March 2020. A total sample of approximately 17.6 million telephone numbers (excluding the territory samples) yielded 59,721 eligible parentals with teens 13-17 years for the RDD phone interview. Among them, 42,668 parentals completed the phone interview about their teen's vaccination history (the whole sample). And among the RDD phone interview completers, 23,994 parentals $(56.2 \%)$ agreed to contact the vaccination providers. In 
the end, among the teens of the RDD phone interview completers, 18,788 teens $(44.0 \%$, "the subsample A") were determined to have adequate provider data, which means "sufficient vaccination history information was obtained from the provider(s) to determine whether the teen is up-to-date with respect to the recommended vaccination schedule." [12] (p. 8). As a result, 23,880 teens of the whole sample (56.0\%, "the subsample B") were not included in the subsample A. For the analyses of the current study, the two subsamples as well as the whole sample of 42,668 teens were used.

\section{HPV unvaccinated teens}

The HPV vaccination status of teens was assessed with the parental reported vaccination information (Method 1) in the whole and subsample A. Parentals responded to the one interview question ("Has teen ever received any human papillomavirus shots?") with four response options (Yes; No; Don't Know; and Refused). HPV unvaccinated teens were defined with teens whose parentals responded to the interview question with "No." In addition, the HPV vaccination status of teens was assessed with the provider reported vaccination information (Method 2) in subsample A. The number of HPV shots, which was determined from the vaccination provider data, was available in the NIS-Teen data. HPV unvaccinated teens were defined with teens whose vaccination providers reported no HPV vaccination.

\section{Socioeconomic status of teens}

Teens' SES was measured with two indicators: mother's education and annual family income. Each indicator was measured with a single interview question.

\section{Covariates}

The following teen-related covariates were considered in the analyses of the current study: age, sex, geographical region, and race/ethnicity. Each of the covariates was measured with a single interview question.

\section{Statistical analyses}

The distributions of sociodemographic characteristics and HPV vaccination status of teens were first examined in the whole sample. Then the distributions were compared between the two subsamples using the Pearson chi-square test. In addition, we compared the parental and the provider reported vaccination information in the subsample A, which was also replicated by each level of SES due to potential SES-differential false positive and false negative percentages under the assumption that the provider reported vaccination information was the reference. The distributions of the proportion of HPV unvaccinated teens were examined by two SES indicators in the whole sample (Method 1) and the subsample A (both Methods 1 and 2). Utilizing multivariate logistic models, the distributions of the proportion of HPV unvaccinated teens by two SES indicators were further examined after controlling for age, sex, race/ethnicity, and region. With consideration of the complex sampling design of the 2019 NIS-Teen, the 
aforementioned analyses were replicated using SPSS 28.0 version of complex samples function. The results were very similar to those with unweighted data. For simplicity, we presented here only the results with the unweighted 2019 NIS-Teen data.

\section{Results}

Sociodemographic distributions of the teens in the whole sample and the two subsamples Table 1 shows the distributions of age, sex, race/ethnicity, region, mother's education, and annual family income in the whole sample and the two subsamples. There were significant differences in all sociodemographic variables except sex between the two subsamples. In general, about $50 \%$ of the teens' mothers were college graduates, while about $10 \%$ of the teens' mothers had less than 12 years as formal education years across the whole sample and three subsamples. Annual family income was also greater than $\$ 75,000$ in about $50 \%$ of the teens, while it was below the poverty level in about $10 \%$ of the teens.

Vaccination status of the teens in the whole sample and the two subsamples In the whole samples, 25,263 (59.2\%) out of 42,668 parentals responded to the HPV shot question with "Yes"; $32.1 \%$ with "No"; 8.6\% with "Don't Know"; and 0.1\% with "Refused" (Table 1). The distribution of the parental responses was generally similar in the two subsamples, although the response with "Yes" increased in the subsample A (64.3\%), while it decreased in the subsample B $(55.2 \%)$.

\section{Comparison of the parental and provider reported vaccination information in the subsample A}

The parental responses to the HPV shot question was compared with the provider information on teen's HPV vaccination in the subsample A. Figure 1 shows that the true-positive percentage of the parental response against the provider information is $82 \%$, while the true-negative percentage is $72.3 \%$. The false-negative percentage ("No" response in the parental report, but $\geq 1$ shot of HPV in the provider report) was $11.1 \%$, while the false-positive percentage ("Yes" response in the parental report, but no shot of HPV in the provider report) was $19.8 \%$. Out of the 18,788 teens in the subsample A, 2,550 teens (13.6\%) were false-negative or false-positive cases.

When the analysis was replicated in each level of two SES indicators in the subsample A, a significant SES differential pattern was observed. The proportions of the false-negative and false-positive cases were highest in the teens with the lowest SES level, while it was lowest in the teens with the highest SES level ( $p<0.001)$ : for example, $20.5 \%$ vs. $11.8 \%$ with mother's education; and $20.2 \%$ vs, $11.4 \%$ with annual family income (Table 2). In particular, the proportion of the false-negative cases were more than two times higher in the teens with the lowest SES level than in the teens with the highest SES level. 


\section{HPV unvaccinated teens (Method 1) by SES in the whole sample}

The proportion of HPV unvaccinated teens (Method 1) was lowest in the teens with the highest SES level with both mother's education and annual family income in the whole sample (Table 3). However, the differences between SES strata were marginal: 4.5 percentage points for mother's education and 2.6 percentage points for annual family income. Interestingly, the proportion of HPV unvaccinated teens were highest in the teens with the middle SES levels $(>12$ years, non-college graduates; and above poverty level, but not greater than $\$ 75 \mathrm{~K}$ ). On the other hand, parental "Yes" responses to the interview question did significantly vary by their mother's education level (63.7\% vs. 47.5\%) and "Don't Know" responses were inversely associated with mother's education levels (6.3\% vs. $21.5 \%)$. Similar patterns were observed with annual family income in the whole sample (Table 3).

\section{HPV unvaccinated teens (Method 1 and Method 2) by SES in the subsamples A}

In the subsample A, the distributions of HPV unvaccinated teens (Method 1) by mother's education and annual family income were similar as in the whole sample (Table 4). When Method 2 (provider reported vaccination) was applied in the subsample A, a quite different pattern was observed (Table 5): the proportion of HPV unvaccinated teens was lowest in the teens with the lowest SES level, while it was highest in the teens with the middle SES levels (6.6 percentage points difference with mother's education and 5.6 percentage points difference with annual family income).

\section{Multivariate analyses of HPV unvaccinated teens by SES in the whole sample and the subsample} A.

Table 6 shows the results of multivariate analyses for HPV unvaccinated teens by SES after controlling for age, sex, race/ethnicity, and region in the whole sample (Method 1) and the subsample A (Method 1 and Method 2). The results were consistent with those in the univariate analyses above. In the whole sample and the subsample A, the multivariate odds of HPV unvaccinated teens (Method 1) was slightly, albeit statistically significant, greater in the teens with the lowest SES level than in the teens with the highest level of mother's education or annual family income: odds ratios (ORs), 1.11 1.12 vs. 1.00; and 1.05 1.10 vs. 1.00, respectively. By contrast, the multivariate odds of HPV unvaccinated teens (Method 2) in the subsample A was the opposite. It was lower in the teens with the lowest SES level than in the teens with the highest level of mother's education or annual family income: ORs, 0.81 and 0.84 vs. 1.00, respectively. Nonetheless, regardless of Method 1 and Method 2, the odds of HPV unvaccinated teens was highest in the teens with the middle level of SES levels (>12 years, non-college graduates; and above poverty level, but not greater than $\$ 75 \mathrm{~K}$ ): ORs (compared to the teens with the highest SES level), 1.27 1.33 and 1.10 1.12, respectively.

\section{Discussion}


To the best of our knowledge, this was the first study demonstrating the direction of social inequality in HPV vaccination along the SES strata of teens can be reversed, depending on the source of teen vaccination information in the NIS-Teen data. In both SES measures, the proportion of HPV unvaccinated teens were lowest in the highest SES level in analyses with parental reported vaccination status. By contrast, it was lowest in the lowest SES level in analyses with provider reported vaccination status. The false negative propensity of parental reported vaccination status was greatest in the lowest SES level, which may be a major reason for the contrasting pattern of social inequality in HPV vaccination between the lowest and highest SES levels. Nonetheless, regardless of the source of teen vaccination information, the proportion of HPV unvaccinated teens was highest in the teens with the middle SES level (>12 years, non-college graduates; and above poverty level, but not greater than $\$ 75 \mathrm{~K}$ ).

Our finding with parental reported vaccination status is consistent with the previous two studies [7-8]. However, the previous studies neither used provider reported data nor considered SESdifferential false-negative of parental reported vaccination information, which was observed in the current study as in the previous validation study of the NIS-Teens [11]. Our finding with provider reported vaccination records is also consistent with the previous study [9]. Walker et al [9] showed that the HPV vaccination rate was higher in the below poverty level than in at or above the poverty level of teens using the 2018 NIS-Teen. However, we think that our finding is more robust because our finding was confirmed with not only annual family income, but also mother's education and after controlling for several potential confounders. In addition, the study by Walker et al [9], the comparison was a two-group comparison (below the poverty level or not) rather a three-group comparison of annual family incomes in the current study so it could not detect any significant difference in the HPV vaccination between the two groups (> $\$ 75 \mathrm{~K}$ or not) at or above the poverty level.

This study has several important implications for research and public health policies on social inequality in HPV vaccination among US teens. First, despite the increasing rates of HPV vaccination over the recent years $[9,13]$, our study highlighted that HPV vaccination rates continue to be disparate by SES status of teens. There is no evidence that social inequality in terms of cervical cancer mortality has been reduced over the past six decades [14]. HPV vaccination of teenagers, as a major public health tool for prevention of cervical and other cancers among teenagers, should be equitably administered between lines of socioeconomic background of teenagers. Second, in our study, a non-linear social inequality in HPV vaccination among US teens was observed. Most interestingly, we observed that the odds of HPV unvaccinated teens in the extreme ends of the SES spectrum (of both mother's education and annual family income) was in fact lower than those in the middle SES categories. More in-depth studies [15] are needed to confirm and elucidate the underlying reasons for the non-linear social inequality in HPV vaccination among US teens in the future. If confirmed in future studies, this may imply that instead of focusing solely on the extreme ends of the SES spectrum, public health 
policy makers need to ramp up HPV vaccination in the teens with the middle SES categories who may be comparatively lagging behind teens of high-end and low-end SES. Third, this study underscored the importance of using provider reported vaccination information over parental reported vaccination status when it comes to social inequality research on HPV and other vaccines using the NIS-Teen data. Otherwise, studies with only parental reported vaccination status (Method 1) in the NIS-Teen data may lead to erroneous conclusions due to possible SESdifferential false-negative propensity. Fourth, on the other hand, a future widespread use of CDC's immunization information systems (IISs) in the US may function as a tool to increase the quality of teen vaccination information from parentals or healthcare providers, leading to more accurate and more inclusive data, statistical analyses, and trends that can dictate future trends to decrease social inequality in teens' HPV vaccination rates.

Our study has some limitations. In our study, we utilized only a single year of data from the NISTeen due to our main focus on the methodological issues in the current study. Thus, the findings of our study remain to be confirmed in the future studies with recent multi-year NIS-Teen data. In our study, about $44 \%$ of the whole sample (subsample A) had adequate provider data. There were some significant differences in sociodemographic variables between the subsample A and subsample B (56\% of the whole sample). However, the results of our study were very similar between the whole sample and the subsample A with Method 1. The main difference in our findings was made by which method, not which subsample. We did not analyze the reasons for the observed nonlinear social inequality in HPV vaccination among US teens, which goes beyond the research question of the current study. We plan to examine any SES differential profiles of the reasons for being unvaccinated against high-risk HPV types among US teens in the near future. 
Author Contributions: Conceptualization, S.C. and B.C.; methodology, B.C.; formal analysis, B.C. ; investigation, B.C. and S.C.; writing-original draft preparation, S.C. (Introduction and Discussion) and B.C. (Materials and Methods, and Results); writing-review and editing, B.C. and S.C.; Visualization, S.C. All authors have read and agreed to the published version of the manuscript.

Funding: This research received no external funding.

Institutional Review Board Statement: Not applicable. This study was a secondary analysis using data from the 2019 NIS-Teen, which is available to the public for research.

Informed Consent Statement: Informed consent was obtained from all subjects involved in the 2019 NIS-Teen study

Data Availability Statement: The NIS-Teen public-use data file is located at http://www.cdc.gov/vaccines/imz-managers/nis/datasetsteen.html.

Conflicts of Interest: The authors declare no conflict of interest. 


\section{References}

1. Watson, M; Saraiya, M; Ahmed, F.; Cardinez, C.J.; Reichman, M.E.; Weir, H.K.; Richards, T.B. Using population-based cancer registry data to assess the burden of human papillomavirus-associated cancers in the United States: overview of methods. Cancer 2008, 113(10 Suppl), 2841-2854.

2. Saraiya, M.; Unger, E.R.; Thompson, T.D.; Lynch, C.F.; Hernandez, B.Y.; Lyu, C.W.; Steinau, M.; Watson, M.; Wilkinson, E.J.; Hopenhayn, C.; Copeland, G.; Cozen, W.; Peters, E.S.; Huang, Y.; Saber, M.S.; Altekruse, S.; Goodman, M.T.; HPV Typing of Cancers Workgroup. US assessment of HPV types in cancers: implications for current and 9-valent HPV vaccines. J Natl Cancer Inst 2015, 107(6), djv086.

3. How Many Cancers Are Linked with HPV Each Year? Available from https://www.cdc.gov/cancer/hpv/statistics/cases.htm (Accessed on Dec 13, 2021)

4. Human Papillomavirus (HPV) Vaccines. Available from https://www.cancer.gov/aboutcancer/causes-prevention/risk/infectious-agents/hpv-vaccine-fact-sheet (Accessed on Dec 13, 2021)

5. Rosenblum, H.G.; Lewis, R.M.; Gargano, J.W.; Querec, T.D.; Unger, E.R.; Markowitz, L.E. Declines in prevalence of human papillomavirus vaccine-type infection among females after introduction of vaccine - United States, 2003-2018. MMWR Morb Mortal Wkly Rep. 2021, 70(12), 415-420.

6. Immunization and Infectious Diseases. Available from https://www.healthypeople.gov/2020/topics-objectives/topic/immunization-andinfectious-diseases/objectives (Accessed on Dec 13, 2021)

7. Xie, Z. The correlation between HPV vaccination rate and income inequality. Health Informatics - An International Journal(HIIJ) 2020, 9(4), 17-27. Available from https://aircconline.com/hiij/V9N4/9420hiij02.pdf (Accessed on Dec 13, 2021)

8. Polonijo, A.N.; Carpiano, R.M.Social inequalities in adolescent human papillomavirus (HPV) vaccination: a test of fundamental cause theory. Soc Sci Med. 2013, 82, 115-125.

9. Walker, T.Y.; Elam-Evans, L.D.; Yankey, D.; Markowitz, L.E.; Williams, C.L.; Fredua, B.; Singleton, J.A.; Stokley, S. National, regional, state, and selected local area vaccination coverage among adolescents aged 13-17 years - United States, 2018. MMWR Morb Mortal Wkly Rep. 2019, 68(33), 718-723. 
10. Dorell, C.G.; Jain, N.; Yankey, D. Validity of parent-reported vaccination status for adolescents aged 13-17 years: National Immunization Survey-Teen, 2008. Public Health Rep. 2011, 126 Suppl 2(Suppl 2), 60-69.

11. Ojha, R.P.; Tota, J.E.; Offutt-Powell, T.N.; Klosky, J.L.; Ashokkumar, R.; Gurney, J.G.The accuracy of human papillomavirus vaccination status based on adult proxy recall or household immunization records for adolescent females in the United States: results from the National Immunization Survey-Teen. Ann Epidemiol. 2013, 23(5), 281-285.

12. National Immunization Survey-Teen: A User's Guide for the 2019 Public-Use Data File. Available from https://www.cdc.gov/vaccines/imz-managers/nis/downloads/NIS-TEENPUF19-DUG.pdf (Accessed on Dec 13, 2021)

13. Boersma, P.; Black, L.I. Human papillomavirus vaccination among adults aged 18-26, 2013-2018. NCHS Data Brief 2020, 354, 1-8.

14. Singh, G.K.; Jemal, A. Socioeconomic and racial/ethnic disparities in cancer mortality, incidence, and survival in the United States, 1950-2014: Over six decades of changing patterns and widening inequalities. J Environ Public Health. 2017, 2017:2819372. doi: $10.1155 / 2017 / 2819372$.

15. Cheruvu, V.K.; Bhatta, M.P.; Drinkard, L.N. Factors associated with parental reasons for "no-intent" to vaccinate female adolescents with human papillomavirus vaccine: National Immunization Survey - Teen 2008-2012. BMC Pediatr. 2017, 17(1), 52. doi: 10.1186/s12887-017-0804-1. 


\begin{tabular}{|c|c|c|c|}
\hline & & \multicolumn{2}{|c|}{ Frequency: N (\%) } \\
\hline & & \multicolumn{2}{|c|}{ Provider-reported Record } \\
\hline & & Yes & No \\
\hline \multirow{5}{*}{$\begin{array}{c}\text { Parental-reported } \\
\text { Response: (Any HPV } \\
\text { Shot?) }\end{array}$} & Yes & $\begin{array}{c}\text { 11,024 (82.0) } \\
\text { (True-positive) }\end{array}$ & $\begin{array}{l}\text { 1,062 (19.8) } \\
\text { (False-positive) }\end{array}$ \\
\hline & No & $\begin{array}{l}\text { 1,488 (11.1) } \\
\text { (False-negative) }\end{array}$ & $\begin{array}{c}\text { 3,867 (72.3) } \\
\text { (True-negative) }\end{array}$ \\
\hline & Don't Know & $922(6.9)$ & $420(7.8)$ \\
\hline & Refused & $2(0.0)$ & $3(0.1)$ \\
\hline & Total & $13,436(100.0)$ & $5,352(100.0)$ \\
\hline
\end{tabular}

Figure 1. Comparison of the parental reported vaccination status against the provider reported vaccination record on the teens in the subsample $A(N=18,788)$ 
Table 1. Sociodemographic characteristics of the whole sample and the two subsamples of teens in the 2019 NIS-Teen data

\begin{tabular}{|c|c|c|c|c|}
\hline \multirow{2}{*}{ Category } & \multirow{2}{*}{ Sub-category } & \multicolumn{3}{|c|}{ Frequency: N (\%) } \\
\hline & & $\begin{array}{l}\text { In the whole sample } \\
\text { (Total } N=42,668 \text { ) }\end{array}$ & $\begin{array}{l}\text { In the subsample A } \\
\text { (Total } \mathrm{N}=18,788 \text { ) }\end{array}$ & $\begin{array}{l}\text { In the subsample } \mathrm{B} \\
\text { (Total } \mathrm{N}=23,880 \text { ) }\end{array}$ \\
\hline \multirow[t]{5}{*}{ Age } & 13 years & $8,500(19.9)$ & $3,927(20.9)^{*}$ & $4,573(19.1)^{*}$ \\
\hline & 14 years & $8,789(20.6)$ & $4,007(21.3)^{*}$ & $4,782(20.0)^{*}$ \\
\hline & 15 years & $8,635(20.2)$ & $3,753(20.0)^{*}$ & $4,882(20.4)^{*}$ \\
\hline & 16 years & $8,703(20.4)$ & $3,753(20.0)^{*}$ & $4,950(20.7)^{*}$ \\
\hline & 17 years & $8,041(18.8)$ & $3,348(17.8)^{*}$ & $4,693(19.7)^{*}$ \\
\hline \multirow[t]{2}{*}{ Sex } & Men & $22,293(52.2)$ & $9,872(52.5)$ & $12,421(52.0)$ \\
\hline & Women & $20,375(47.8)$ & $8,916(47.5)$ & $11,459(48.0)$ \\
\hline \multirow[t]{4}{*}{ Race/Ethnicity } & Hispanic & $8,168(19.1)$ & $3,466(18.4)^{*}$ & $4,702(19.7)^{*}$ \\
\hline & Non-Hispanic White & $26,014(61.0)$ & $11,883(63.2)^{*}$ & $14,131(59.2)^{*}$ \\
\hline & Non-Hispanic Black & $3,730(8.7)$ & $1,365(7.3)^{*}$ & $2,365(9.9)^{*}$ \\
\hline & $\begin{array}{l}\text { Non-Hispanic Other } \\
\text { and Multiple Race }\end{array}$ & $4,756(11.1)$ & $2,074(11.0)^{*}$ & $2,682(11.2)^{*}$ \\
\hline \multirow[t]{4}{*}{ Region } & Northeast & $8,107(19.0)$ & $3,597(19.1)^{*}$ & $4,510(18.9)^{*}$ \\
\hline & Midwest & $8,623(20.2)$ & $3,985(21.2)^{*}$ & $4,638(19.4)^{*}$ \\
\hline & South & $16,945(39.7)$ & $7,057(37.6)^{*}$ & $9,888(41.4)^{*}$ \\
\hline & West & $8,993(21.1)$ & $4,149(22.1)^{*}$ & $4,844(20.3)^{*}$ \\
\hline \multirow{3}{*}{$\begin{array}{l}\text { Mother's } \\
\text { education }\end{array}$} & $<12$ years & 4,107 (9.6) & $1,778(9.5)^{*}$ & $2,329(9.8)^{*}$ \\
\hline & 12 years & $6,585(15.4)$ & $2,680(14.3)^{*}$ & $3,905(16.4)^{*}$ \\
\hline & > 12 years, Non- & $11,199(26.2)$ & $4,921(26.2)^{*}$ & $6,278(26.3)^{*}$ \\
\hline
\end{tabular}




\begin{tabular}{|c|c|c|c|c|}
\hline & College Graduate & & & \\
\hline & College Graduate & 20,777 (48.7) & $9,409(50.1)^{*}$ & $11,368(47.6)^{*}$ \\
\hline \multirow[t]{4}{*}{$\begin{array}{l}\text { Annual Family } \\
\text { Income }\end{array}$} & $\begin{array}{l}\text { Above poverty level, > } \\
\$ 75 \mathrm{~K}\end{array}$ & $21,891(51.3)$ & $10,061(53.6)^{*}$ & $11,830(49.5)^{*}$ \\
\hline & $\begin{array}{l}\text { Above poverty } \\
\text { level, } \leq 75 \mathrm{~K}\end{array}$ & $11,954(28.0)$ & $5,264(28.0)^{*}$ & $6,690(28.0)^{*}$ \\
\hline & Below poverty level & $5,885(13.8)$ & $2,803(14.9)^{*}$ & $3,082(12.9)^{*}$ \\
\hline & Unknown & $2,938(6.9)$ & $660(3.5)^{*}$ & $2,278(9.5)^{*}$ \\
\hline \multirow[t]{4}{*}{ Any HPV shot? } & Yes & $25,263(59.2)$ & $12,086(64.3)^{*}$ & $13,177(55.2)^{*}, \emptyset$ \\
\hline & No & $13,701(32.1)$ & $5,355(28.5)^{*}$ & $8,346(34.9)^{*}$ \\
\hline & Don’t Know & $3,680(8.6)$ & $1,342(7.1)^{*}$ & $2,338(9.8)^{*}$ \\
\hline & Refused & $24(0.1)$ & $5(0.0)^{*}$ & $19(0.1)^{*}$ \\
\hline
\end{tabular}

*Chi-square test: $\mathrm{P}<0.001$. 
Table 2. The false-negative and false-positive cases of the parental reported HPV vaccination information against the provider reported vaccination information in each of SES indicators in the subsample A $(\mathrm{N}=18,788)$

\begin{tabular}{|c|c|c|c|c|}
\hline \multirow{2}{*}{ Category } & \multirow{2}{*}{ Sub-category } & \multicolumn{3}{|c|}{ Frequency (\%) } \\
\hline & & False negative (A) & False-positive (B) & $\mathrm{A}$ or $\mathrm{B}$ \\
\hline \multirow{4}{*}{$\begin{array}{l}\text { Mother's } \\
\text { education }\end{array}$} & $<12$ years & $277 / 1,405(19.7)^{* *}$ & $88 / 373(23.6)^{*}$ & $365 / 1,778(20.5)^{* *}$ \\
\hline & 12 years & $280 / 1,906(14.7)^{* * *}$ & $151 / 774(19.5)^{*}$ & $431 / 2,680(16.1)^{* *}$ \\
\hline & $\begin{array}{l}>12 \text { years, Non- } \\
\text { College Graduate }\end{array}$ & $365 / 3,325(11.0)^{* *}$ & $281 / 1,596(17.6)^{*}$ & $646 / 4,921(13.1)^{* *}$ \\
\hline & College Graduate & $566 / 6,800(8.3)^{* *}$ & $542 / 2,609(20.8)^{*}$ & $1,108 / 9,409(11.8)^{* *}$ \\
\hline \multirow[t]{4}{*}{$\begin{array}{l}\text { Annual Family } \\
\text { Income }\end{array}$} & $\begin{array}{l}\text { Above poverty level, > } \\
\$ 75 \mathrm{~K}\end{array}$ & $589 / 7,139(8.3)^{* *}$ & $557 / 2,922(19.1)^{*}$ & $1,146 / 10,061(11.4)^{* *}$ \\
\hline & $\begin{array}{l}\text { Above poverty } \\
\text { level, } \leq 75 \mathrm{~K}\end{array}$ & $427 / 3,677(11.6)^{* *}$ & $312 / 1,587(19.7)^{*}$ & $739 / 5,264(14.0)^{* *}$ \\
\hline & Below poverty level & $405 / 2,146(18.9)^{* *}$ & $161 / 657(24.5)^{*}$ & $566 / 2,803(20.2)^{* *}$ \\
\hline & Unknown & $67 / 474(14.1)^{* *}$ & $32 / 186(17.2)^{*}$ & $99 / 660(15.0)^{* *}$ \\
\hline
\end{tabular}

Chi-square test: $\mathrm{P}^{* *}<0.001, \mathrm{P}^{*}<0.05$. 
Table 3. The proportion of HPV unvaccinated teens with one single interview question (Method 1: "No" responses) in the whole sample $(\mathrm{N}=42,668)$

\begin{tabular}{|c|c|c|c|c|c|}
\hline \multirow{3}{*}{$\begin{array}{l}\text { Socioeconom } \\
\text { ic status } \\
\text { indicator }\end{array}$} & \multirow[t]{3}{*}{ Level or category } & \multicolumn{4}{|c|}{ Question: Has teen ever received any human papillomavirus shots? } \\
\hline & & $\begin{array}{c}\text { Yes } \\
(59.2 \%)\end{array}$ & $\begin{array}{c}\text { No } \\
(32.1 \%)\end{array}$ & $\begin{array}{c}\text { Don't Know } \\
(8.6 \%)\end{array}$ & $\begin{array}{l}\text { Refused } \\
(0.1 \%)\end{array}$ \\
\hline & & $\mathrm{n}=25,263$ & $\mathrm{n}=13,701$ & $\mathrm{n}=3,680$ & $\mathrm{n}=24$ \\
\hline \multirow[t]{4}{*}{$\begin{array}{l}\text { Mother's } \\
\text { education }\end{array}$} & $<12$ years & $\begin{array}{c}1,949 \\
(47.5 \%)\end{array}$ & $\begin{array}{c}1,273^{*} \\
(31.0 \%)\end{array}$ & $\begin{array}{c}884 \\
(21.5 \%)\end{array}$ & $\begin{array}{c}1 \\
(0.0 \%)\end{array}$ \\
\hline & 12 years & $\begin{array}{c}3,587 \\
(54.5 \%)\end{array}$ & $\begin{array}{c}2,244^{*} \\
(34.1 \%)\end{array}$ & $\begin{array}{c}750 \\
(11.4 \%)\end{array}$ & $\begin{array}{c}4 \\
(0.1 \%)\end{array}$ \\
\hline & $\begin{array}{l}>12 \text { years, Non-College } \\
\text { Graduate }\end{array}$ & $\begin{array}{c}6,484 \\
(57.9 \%)\end{array}$ & $\begin{array}{c}3,972^{*} \\
(35.5 \%)\end{array}$ & $\begin{array}{c}736 \\
(6.6 \%)\end{array}$ & $\begin{array}{c}7 \\
(0.1 \%)\end{array}$ \\
\hline & College Graduate & $\begin{array}{c}13,243 \\
(63.7 \%)\end{array}$ & $\begin{array}{c}6,212^{*} \\
(29.9 \%)\end{array}$ & $\begin{array}{c}1,310 \\
(6.3 \%)\end{array}$ & $\begin{array}{c}12 \\
(0.1 \%)\end{array}$ \\
\hline \multirow{4}{*}{$\begin{array}{l}\text { Annual } \\
\text { Family } \\
\text { Income }\end{array}$} & $\begin{array}{l}\text { Above poverty level, > } \\
\$ 75 \mathrm{~K}\end{array}$ & $\begin{array}{c}13,691 \\
(62.5 \%)\end{array}$ & $\begin{array}{c}6,849^{*} \\
(31.3 \%)\end{array}$ & $\begin{array}{c}1,338 \\
(6.1 \%)\end{array}$ & $\begin{array}{c}13 \\
(0.1 \%)\end{array}$ \\
\hline & $\begin{array}{l}\text { Above poverty } \\
\text { level, } \leq 75 \mathrm{~K}\end{array}$ & $\begin{array}{c}6,854 \\
(57.3 \%)\end{array}$ & $\begin{array}{c}4,049^{*} \\
(33.9 \%)\end{array}$ & $\begin{array}{c}1,046 \\
(8.8 \%)\end{array}$ & $\begin{array}{c}5 \\
(0.0 \%)\end{array}$ \\
\hline & Below poverty level & $\begin{array}{c}3,178 \\
(54.0 \%)\end{array}$ & $\begin{array}{c}1,848^{*} \\
(31.4 \%)\end{array}$ & $\begin{array}{c}858 \\
(14.6 \%)\end{array}$ & $\begin{array}{c}1 \\
(0.0 \%)\end{array}$ \\
\hline & Unknown & $\begin{array}{c}1,540 \\
(52.4 \%)\end{array}$ & $\begin{array}{c}955^{*} \\
(32.5 \%)\end{array}$ & $\begin{array}{c}438 \\
(14.9 \%)\end{array}$ & $\begin{array}{c}5 \\
(0.2 \%)\end{array}$ \\
\hline
\end{tabular}

Chi-square test for "No" responses vs the other three responses by SES level. "P < 0.001 . 
Table 4. The proportion of HPV unvaccinated teens with one single interview question (Method 1: "No" responses) in the subsample A $(\mathrm{N}=18,788)$

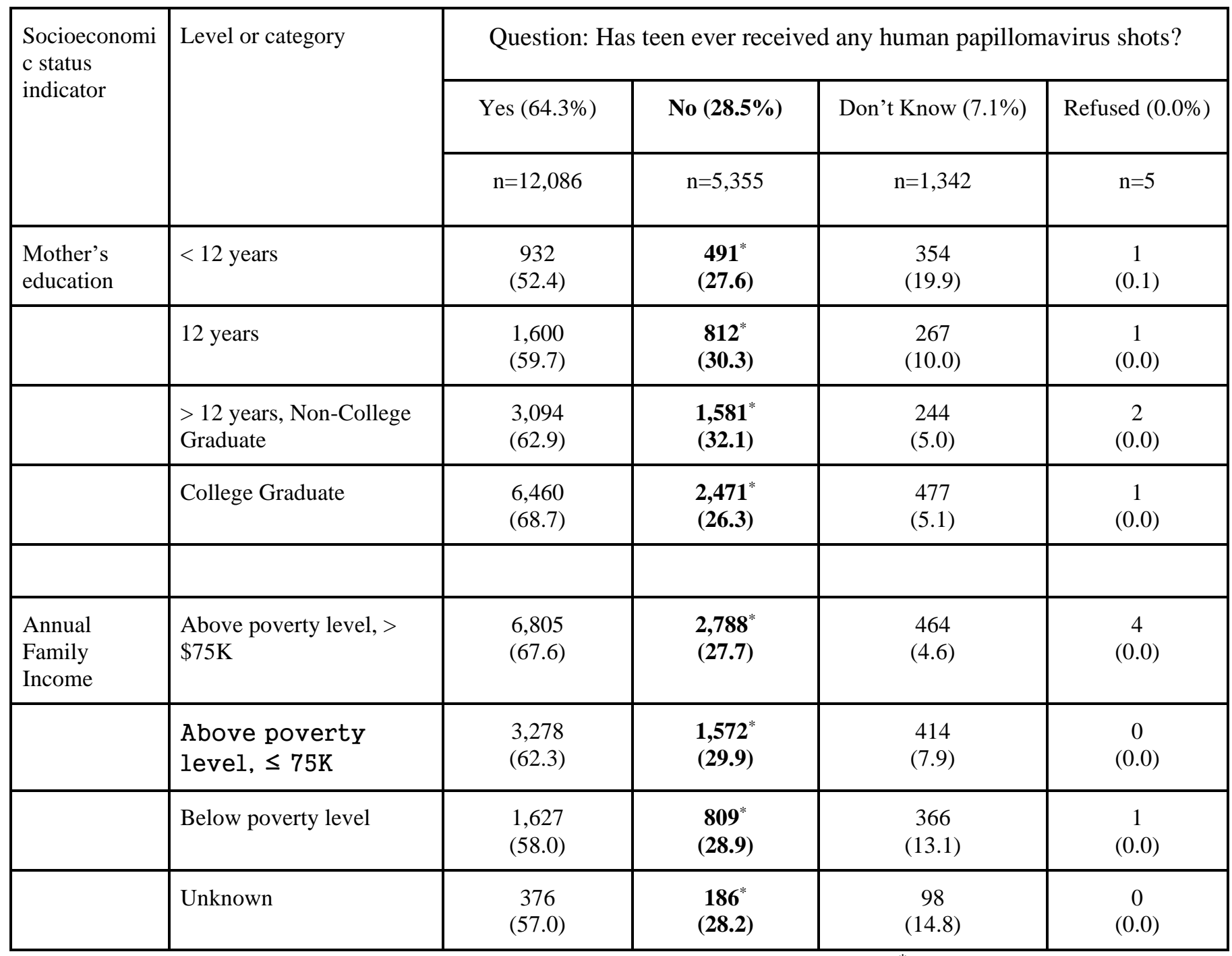

Chi-square test for "No" responses vs the other three responses by SES level. ${ }^{*} \mathrm{P}<0.001$. 
Table 5. The proportion of HPV unvaccinated teens with the provider reported vaccination information (Method 2: "No" vaccination) in the subsample A $(\mathrm{N}=18,788)$

\begin{tabular}{|c|c|c|c|}
\hline \multirow{3}{*}{$\begin{array}{l}\text { Socioeconomic } \\
\text { status indicator }\end{array}$} & \multirow[t]{3}{*}{ Level or category } & \multicolumn{2}{|c|}{ Provider-reported vaccination } \\
\hline & & Yes $(71.5 \%)$ & No $(28.5 \%)$ \\
\hline & & $n=13,436$ & $\mathrm{n}=5,352$ \\
\hline \multirow[t]{4}{*}{ Mother's education } & $<12$ years & $\begin{array}{l}1,405 \\
(79.0)\end{array}$ & $\begin{array}{l}\text { 373 }^{*} \\
(21.1)\end{array}$ \\
\hline & 12 years & $\begin{array}{l}1,906 \\
(71.1)\end{array}$ & $\begin{array}{l}\mathbf{7 7 4}^{*} \\
(28.9)\end{array}$ \\
\hline & $\begin{array}{l}>12 \text { years, Non-College } \\
\text { Graduate }\end{array}$ & $\begin{array}{l}3,325 \\
(67.6)\end{array}$ & $\begin{array}{l}1,596 * \\
(32.4)\end{array}$ \\
\hline & College Graduate & $\begin{array}{l}6,800 \\
(72.3)\end{array}$ & $\begin{array}{l}2,609^{*} \\
(27.7)\end{array}$ \\
\hline \multirow[t]{4}{*}{$\begin{array}{l}\text { Annual Family } \\
\text { Income }\end{array}$} & $\begin{array}{l}\text { Above poverty level, > } \\
\$ 75 \mathrm{~K}\end{array}$ & $\begin{array}{l}7,139 \\
(71.1)\end{array}$ & $\begin{array}{l}2,922 \\
(29.0)\end{array}$ \\
\hline & $\begin{array}{l}\text { Above poverty } \\
\text { level, } \leq 75 \mathrm{~K}\end{array}$ & $\begin{array}{l}3,677 \\
(69.9)\end{array}$ & $\begin{array}{l}1,587^{*} \\
(30.1)\end{array}$ \\
\hline & Below poverty level & $\begin{array}{l}2,146 \\
(76.6)\end{array}$ & $\begin{array}{c}657^{*} \\
(23.4)\end{array}$ \\
\hline & Unknown & $\begin{array}{c}474 \\
(71.8)\end{array}$ & $\begin{array}{c}186^{*} \\
(28.2)\end{array}$ \\
\hline
\end{tabular}

Chi-sqaure test: ${ }^{*} \mathrm{P}<0.001$. 
Table 6. The multivariate logistic regression models for HPV unvaccinated teens (Method 1 and Method 2) by socioeconomic status after controlling for age, sex, race/ethnicity, and region in the whole sample and the subsample A $(\mathrm{N}=18,788)$

\begin{tabular}{|c|c|c|c|c|}
\hline \multirow[b]{2}{*}{$\begin{array}{l}\text { Socioeconomic } \\
\text { status indicator }\end{array}$} & \multirow[b]{2}{*}{ Category } & \multicolumn{3}{|c|}{ Odd ratio (95\% Confidence Interval) for HPV unvaccinated teens } \\
\hline & & $\begin{array}{l}\text { In the whole sample } \\
\text { (Method 1) }\end{array}$ & $\begin{array}{l}\text { In the subsample A } \\
\text { (Method 1) }\end{array}$ & $\begin{array}{c}\text { In the subsample A } \\
\text { (Method 2) }\end{array}$ \\
\hline \multirow{4}{*}{$\begin{array}{l}\text { Mother's } \\
\text { education }\end{array}$} & $<12$ years & $1.11(1.03-1.20)$ & $1.12(0.99-1.27)$ & $0.81(0.71-0.92)$ \\
\hline & 12 years & $1.24(1.17-1.32)$ & $1.25(1.14-1.38)$ & $1.13(1.02-1.24)$ \\
\hline & $\begin{array}{l}>12 \text { years, Non- } \\
\text { College Graduate }\end{array}$ & $1.29(1.22-1.35)$ & $1.33(1.23-1.44)$ & $1.27(1.18-1.37)$ \\
\hline & College Graduate & 1.00 & 1.00 & 1.00 \\
\hline \multirow[t]{4}{*}{$\begin{array}{l}\text { Annual Family } \\
\text { Income }\end{array}$} & $\begin{array}{l}\text { Above poverty } \\
\text { level, }>\$ 75 \mathrm{~K}\end{array}$ & 1.00 & 1.00 & 1.00 \\
\hline & $\begin{array}{l}\text { Above } \\
\text { poverty level, } \\
\leq 75 \mathrm{~K}\end{array}$ & $1.14(1.08-1.19)$ & $1.12(1.04-1.21)$ & $1.10(1.02-1.18)$ \\
\hline & $\begin{array}{l}\text { Below poverty } \\
\text { level }\end{array}$ & $1.05(0.98-1.12)$ & $1.10(1.00-1.21)$ & $0.84(0.76-0.94)$ \\
\hline & Unknown & $1.10(1.01-1.19)$ & $1.07(0.90-1.28)$ & $1.06(0.89-1.27)$ \\
\hline
\end{tabular}


